\author{
В.Й. Климченко ${ }^{1}$ О.С. Маляренко ${ }^{1}$, О.В. Бєлавін ${ }^{2}$, М.І. Рожков ${ }^{1}$ \\ ${ }^{1}$ Харківський національний університет Повітряних Сил ім. І. Кожедуба, Харків \\ ${ }^{2}$ Командування Повітряних Сил Збройних Сил Украйни, Вінниця
}

\title{
ВИЗНАЧЕННЯ ВЕРХНЬОЇ МЕЖІ ЗОНИ ВИЯВЛЕННЯ ЦІЛЕЙ ОГЛЯДОВИМИ РЛС ЕКСПЕРИМЕНТАЛЬНО-АНАЛІТИЧНИМ СПОСОБОМ
}

\begin{abstract}
Розглядається варіант поєднання аналітично-розрахункових методів визначення зон виявлення повітряних об'єктів (ПО) з обмеженим обсягом експериментальних перевірок, які здійснюються через обліт спеціальними літальними апаратами або ж через побіжне використання польотів рейсових ПО. Завдяки такому поєднанню, верхня межа зони може бути розрахована за експериментальними даними, отриманими через обліт на одній заданій висоті спеціально виділеним літаком або ж за даними супроводження рейсових літаків, висота польоту яких завчасно відома. Визначення верхньої межі зони виявлення ПО здійснюється через аналіз амплітуди прийнятих ехо-сигналів в прочесі супроводження спеціальних літальних апаратів або рейсових літаків.
\end{abstract}

Ключові слова: оглядові радіолокаційні станції, зона виявлення повітряних об'єктів, обліт, випробування.

\section{Вступ}

Постановка проблеми. Реалізація випробувань РЛС з використанням льотних перевірок є надзвичайно витратною і вимагає залучення значних коштів та матеріальних засобів. 3 урахуванням обмежених можливостей полігонної бази України [1; 2] такі випробування можуть бути проведені лише частково. Брак експериментальних перевірок має бути компенсованим розробкою альтернативних методів оцінювання основних тактико-технічних характеристик РЛС, і перш за все - параметрів зони виявлення. Враховуючи сучасні можливості з навігації та обробки радіолокаційної інформації, контроль необхідних параметрів зони виявлення цілей може бути здійснений без проведення обльотів або при суттєвому зменшенні їхньої кількості.

Аналіз останніх досліджень і публікацій. Питанням поєднання аналітично-розрахункових методів визначення зон виявлення ПО з обмеженим обсягом експериментальних перевірок за останні роки присвячено чимало публікацій. В [3; 4] розглядаються методи та способи визначення основних тактико-технічних характеристик РЛС при суттєвому зменшенні їхньої кількості обльотів. В [5-7] переваги надається розробленню імітаційних методів, які б забезпечували якість випробувань і дозволяли проконтролювати необхідні параметри зони виявлення цілей та точнісні характеристики РЛС без проведення обльотів. В [8] розглядаються методи визначення зон виявлення цілей в умовах завад через використання імітаторів активних завад, встановлених на межі дальньої зони. В [9] аналізується метод ітера- ційного визначення дальності виявлення повітряних об'єктів на різних висотах за наявності обмежених експериментальних даних разових обльотів на певній висоті. В [10] здійснюється аналіз реальних можливостей використання випромінювання Сонця для визначення діаграми направленості антени (ДНА) та форми зони виявлення ПО. Методика з визначення окремих параметрів зони виявлення ПО за польотами рейсових літаків викладена в документі [11].

Метою цієї статті $є$ розроблення одного із різновидів експериментально-аналітичного способу визначення верхньої крайки зони виявлення ПО радіолокаційними станціями через накопичення і статистичну обробку даних щодо амплітуди ехосигналів від цілей в процесі їхнього супроводження.

\section{Виклад основного матеріалу}

Зона виявлення цілей будь-якої оглядової РЛС являє собою досить складну просторову фігуру, форма якої залежить від багатьох детермінованих і випадкових чинників. Повну характеристику зони виявлення цілей оглядової РЛС містить набір вертикальних перерізів, здійснених в азимутальних напрямках $\beta_{i}$ з дискретністю, не більшою ніж ширина ДНА в азимутальній площині. Кожен з перерізів описується в сферичній системі координат таким співвідношенням:

$$
r\left(\varepsilon, \beta_{i}\right)=r_{o} \cdot F_{o}(\varepsilon) \cdot \Phi_{3}\left(\varepsilon, \beta_{i}\right),
$$

де $r_{o}$ - максимальна дальність виявлення цілей у вільному просторі, яка визначається енергетичним потенціалом РЛС, типом цілі та умовами поширення 
хвиль і для оглядового радіолокатора може бути подана так [12]:

$$
r_{o}=\sqrt[4]{\frac{P_{c p} T_{o} G_{e} A_{e \phi} \sigma_{u}}{(4 \pi)^{2} \cdot v_{n o p} \cdot L_{\text {РлC }} \cdot k \cdot T \cdot U \cdot L_{3}}}=\sqrt[4]{E \frac{\sigma_{u}}{L_{3}}},
$$

де $P_{c p}-$ середня потужність передавача;

$T_{o}$ - період огляду простору;

$G_{e}-$ направленість зони огляду простору без урахування впливу поверхні Землі, для РЛС кругового огляду $G_{e}=\frac{2}{\int_{0}^{\pi / 2} F_{o}^{2}(\varepsilon) \cdot \cos \varepsilon \cdot d \varepsilon}$;

$A_{e \phi}-$ ефективна площа антени;

$\sigma_{u}$ - ефективна відбиваюча поверхня цілі;

$v_{\text {nоp }}-$ поріг виявлення оброблених ехосигналів;

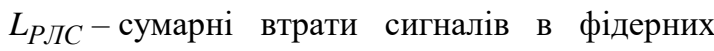
трактах та при обробці;

$k=1,38 \cdot 10-23$ Дж/град - стала Больцмана;

$T \approx 300^{\circ}$ - приведена шумова температура;

$U$ - коефіцієнт шуму приймального пристрою;

$L_{3}$ - затухання електромагнітних коливань при поширенні в атмосфері;

$E$ - енергетичний потенціал РЛС;

$F_{o}(\varepsilon)$ - ДНА за кутом місця у вільному простоpi;

$\Phi_{3}\left(\varepsilon, \beta_{i}\right)$ - множник Землі на і-тому азимутальному напрямку.

Але за реальних умов користуватись співвідношеннями (1) та (2), ) для розрахунку зон виявлення цілей не можна $з$ кількох причин.

По-перше, через невизначеність інтерференційного множника Землі $\Phi_{3}\left(\varepsilon, \beta_{i}\right)$, а по-друге через наближеність розрахунків значення $\mathrm{r}_{\mathrm{o}}$ за співвідношенням (2). Інтерференційний множник Землі $\Phi_{3}\left(\varepsilon, \beta_{i}\right)$ залежить від характеру і стану підстильної поверхні, діапазону хвиль та інших багатьох факторів. Теоретично за ідеальних умов інтерференційний множник в залежності від кута місця $\varepsilon$ може приймати значення [13] від 0 до 2, що означає можливість появи під одними кутами місця нульових провалів в зоні виявлення цілей а під іншими - збільшення дальності виявлення цілей вдвічі. Практично ж ні перше, ні друге не відбувається через те, що коефіцієнт віддзеркалення електромагнітних коливань від поверхні землі завжди менший за одиницю і залежить не тільки від характеру та стану підстильної поверхні, а й від кута падіння $\varepsilon$ електромагнітних коливань. Більше того, в сантиметровому та дециметровому діапазонах хвиль інтерференційним множником $\Phi_{3}\left(\varepsilon, \beta_{i}\right)$, як правило, нехтують. Це пояснюється тим, що в сантиметровому та дециметровому діапазонах хвиль підстильна поверхня перестає бути дзеркальною, а необхідні розміри площадки, яка $є$ суттєвою для віддзеркалення за типових значень висоти піднімання фазового центру антени РЛС, зростають до кількох кілометрів [12], чого важко досягти навіть для рівнинної місцевості. На рис. 1 наведені вертикальні перерізи зон виявлення РЛС різних класів і діапазонів хвиль. Перерізи зон виявлення рис. 1 а, та 1 б, відповідають типовим трикоординатним РЛС сантиметрового та дециметрового діапазонів за умови розташування їх на ідеальних позиціях з коефіцієнтом відбиття підстильної поверхні 0,5 .
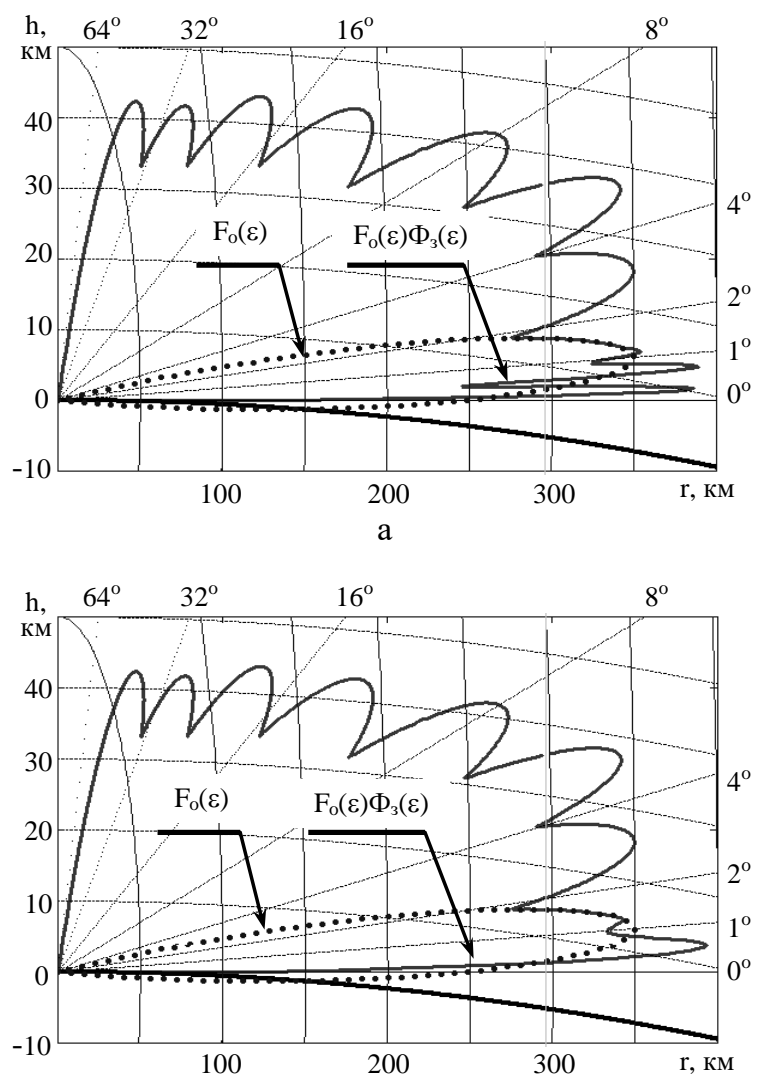

6

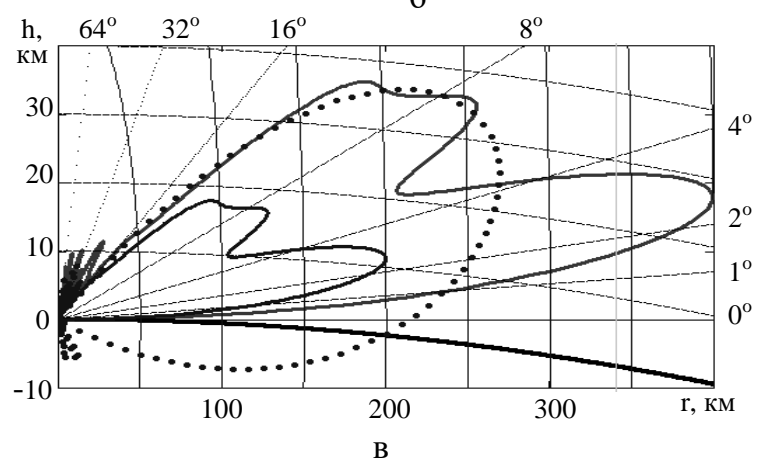

Рис. 1. Вплив поверхні Землі на формування зон виявлення цілей в РЛС різних діапазонів хвиль: $\mathrm{a}$ - сантиметровий діапазон, довжина хвилі $10 \mathrm{~cm}$, висота фазового центру антени 6 м;

б - дециметровий діапазон, довжина хвилі 23 см, висота фазового центру антени 6 м;

в - метровий діапазон, довжина хвилі 1,7 м, висота фазового центру антени $10 \mathrm{M}$ Джерело: розроблено авторами. 
Навіть за таких умов вплив підстильної поверхні позначається незначною мірою лише на нижній крайці першого променю. На реальних же позиціях інтерференція буде ще меншою. Крім того, навіть через незначну зміну рельєфу на різних азимутах характер інтерференції постійно змінюється так, що нижня крайка сукупної ДНА $F_{o}(\varepsilon) \cdot \Phi_{3}(\varepsilon, \beta)$ буде носити флуктуаційний характер відносно $F_{o}(\varepsilon)$. Означені особливості і дають підставу не враховувати в РЛС сантиметрового та дециметрового діапазонів інтерференційний множник $\Phi_{3}(\varepsilon, \beta)$, тобто вважати, що $\Phi_{3}(\varepsilon, \beta)=1$.

Для двокоординатних РЛС метрового діапазону хвиль вплив інтерференційного множника Землі на формування сукупної ДНА на відміну від РЛС сантиметрового та дециметрового діапазонів $є$ визначальним (рис. 1, в). Але точний розрахунок сукупної ДНА також залишається неможливим через велику кількість випадкових чинників, якими характеризується стан підстильної поверхні та рельєф місцевості, де розгорнута РЛС. Реальні ДНА сильно розходяться $з$ розрахунковими, особливо під великими кутами місця.

Спільною рисою зон виявлення цілей усіма оглядовими РЛС контролю повітряного простору незалежно від діапазону хвиль є складний характер зміни верхньої крайки, який розраховується лише теоретично, оскільки визначити його обльотом практично неможливо через необхідність здійснення польотів на висотах в кілька десятків кілометрів.

Частковим вирішенням означеної проблеми $\epsilon$ штучне стиснення зони виявлення цілей через введення в приймальний тракт РЛС каліброваного затухання. Наприклад, при ослабленні прийнятих ехосигналів на 12 дБ зона стискається рівно вдвічі (крива $F_{C T}(\varepsilon)$ на рис. 1, в). В цьому випадку виникає можливість визначення верхньої крайки через обльоти на досяжних висотах від 10 км до 18 км. Такий спосіб визначення верхньої крайки зони виявлення цілей мав застосування при випробуванні таких РЛС великих та середніх висот, як 5Н84А, 5Н87 та ін. Як різновид означеного способу може використовуватися обліт на фіксованій висоті за різних значень послаблення ехосигналів (рис. 2).

Але за такого штучного стиснення зони виявлення цілей методика обльоту залишається незмінною i передбачає багаторазові польоти літаків або на різних висотах, або на фіксованій висоті.

В сучасних РЛС з розвинутою системою документування сигналів та інформації доступною є процедура запису амплітуди прийнятих від цілі ехосигналів в процесі іiї супроводження. Це докорінно змінює можливості з оперативної оцінки зони вияв- лення цілей такими РЛС.

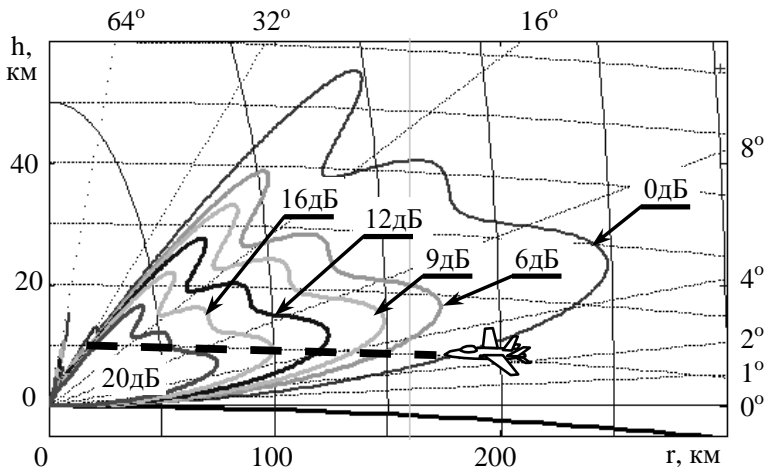

Рис. 2. Зміна розмірів зони виявлення цілей РЛС при введенні ослаблення в тракт обробки сигналів Джерело: розроблено авторами.

Дійсно, в момент входження цілі в зону виявлення на дальності $\mathrm{r}_{\text {в }}$ (рис. 3) амплітуда сигналу $U_{c}$ досягає порогового значення $U_{n}$, тобто відношення "сигнал/поріг”

$$
q=\frac{U_{c}}{U_{n}}=1,
$$

або за логарифмічною шкалою

$$
q_{1}=20 \cdot \lg \frac{U_{c}}{U_{n}}=0 \partial Б .
$$

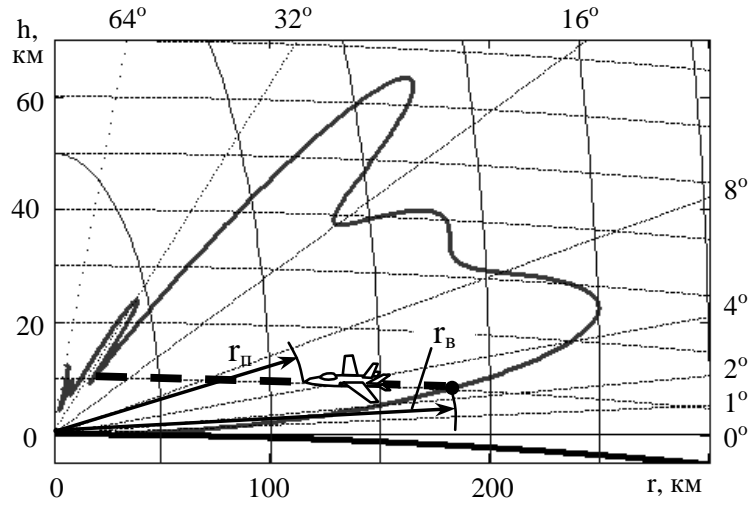

Рис. 3. Вертикальний перетин реальної зони виявлення

Джерело: розроблено авторами.

Якби ціль 3 моменту ії виявлення летіла зі зниженням так, щоб іiі траєкторія польоту точно збігалась 3 нижньою крайкою зони, то відношення (3a, 3б) залишалися б незмінними.

Якщо ж ціль здійснює політ на постійній висоті (див. рис. 3), то вона входить всередину зони, і у міру наближення цілі до точки стояння РЛС амплітуда сигналу буде зростати пропорційно відношенню $\left(\frac{r_{B}}{r_{n}}\right)^{2}$, тобто 


$$
U_{c}=U_{n}\left(\frac{r_{b}}{r_{n}}\right)^{2},
$$

де $r_{n}$ - поточна похила дальність до супроводжуваної цілі;

$r_{6}$ - дальність виявлення цілі під тим кутом місця, під яким на даний момент перебуває супроводжувана ціль.

Підставляючи (4) в (3a, 3б), отримаємо закон зміни відношення “сигнал/поріг” в процесі перетинання ціллю зони виявлення:

$$
\begin{gathered}
q\left(r_{n}\right)=\frac{\left(\frac{r_{b}}{r_{n}}\right)^{2} U_{n}}{U_{n}}=\left(\frac{r_{b}}{r_{n}}\right)^{2}, \\
q_{1}\left(r_{n}\right)=20 \cdot \lg \frac{\left(\frac{r_{B}}{r}\right)^{2} U_{n}}{U_{n}}=40 \cdot \lg \left(\frac{r_{B}}{r_{n}}\right) .
\end{gathered}
$$

На рис. 4 наведена залежність величини відношення “сигнал/поріг” від похилої дальності до цілі, яка перетинає зону виявлення цілей типової оглядової РЛС (рис. 3) на висоті 10 км.

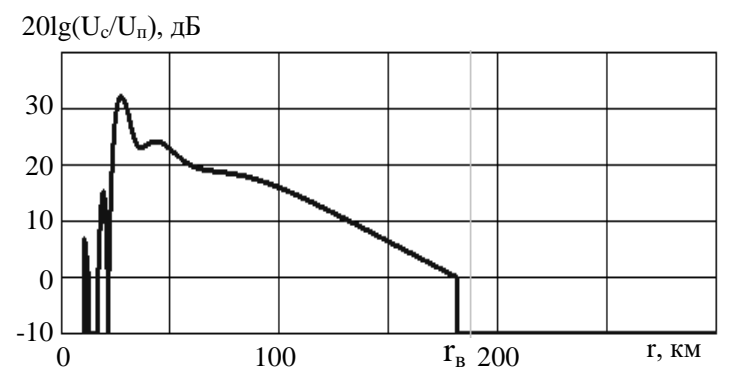

Рис. 4. Характер виміряної залежності відношення “сигнал/поріг” від дальності супроводжуваної цілі

Джерело: розроблено авторами.

Щоб визначити вертикальний перетин зони виявлення за даними супроводження траси цілі, достатньо для кожної точки траси розрахувати кут місця цілі і визначити дальність виявлення цілі під цими кутами. Кут місця розраховується за співвідношенням

$$
\varepsilon\left(r_{n}\right)=\arcsin \left(\frac{h_{u}}{r_{n}}-\frac{r_{n}}{2 R_{3 e}}\right),
$$

де $h_{u}$ - висота польоту цілі;

$$
R_{\text {зе }} \text { - еквівалентний радіус Землі. }
$$

Дальність виявлення цілі під кутом місця $\varepsilon$ розраховується за співвідношенням:

$$
r_{B}=r_{n} \sqrt{q\left(r_{n}\right)}
$$

або

$$
r_{B}=r_{n} 10^{\frac{q 1\left(r_{n}\right)}{20}} .
$$

Отримана сукупність розрахункових даних являє собою вертикальний перетин зони виявлення цілі в сферичній системі координат (рис. 5).

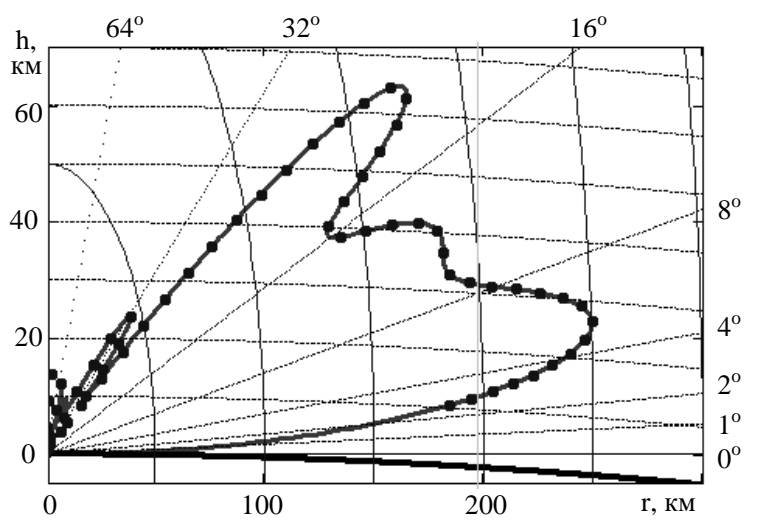

Рис. 5. Розрахована за даними вимірювань верхня крайка зони виявлення: жирні крапки Джерело: розроблено авторами.

Можна не обчислювати кути місця $\varepsilon$, а розрахувати перетин зони виявлення в декартовій системі координат за співвідношеннями:

$$
\begin{aligned}
& \left\{\begin{array}{l}
x_{\theta}\left(r_{n}\right)=r_{n} \cdot \sqrt{q\left(r_{n}\right)} \cos \left[\arcsin \left(\frac{h_{u}}{r_{n}}-\frac{r_{n}}{2 R_{3 e}}\right)\right], \\
y_{6}\left(r_{n}\right)=r_{n} \cdot \sqrt{q\left(r_{n}\right)}\left(\frac{h_{u}}{r_{n}}-\frac{r_{n}}{2 R_{3 e}}\right)
\end{array}\right. \\
& \left\{\begin{array}{l}
x_{B}\left(r_{n}\right)=r_{n} \cdot 10^{\frac{q 1\left(r_{n}\right)}{20}} \cos \left[\arcsin \left(\frac{h_{u}}{r_{n}}-\frac{r_{n}}{2 R_{3 e}}\right)\right] \\
y_{B}\left(r_{n}\right)=r_{n} \cdot 10^{\frac{q 1\left(r_{n}\right)}{20}}\left(\frac{h_{u}}{r_{n}}-\frac{r_{n}}{2 R_{3 e}}\right)
\end{array} .\right.
\end{aligned}
$$

В обох випадках розрахунок зони виявлення здійснюється лише в області існування запису $q\left(r_{n}\right)$ чи $q 1\left(r_{n}\right)$, тобто в секторі кутів місця вищому за той кут місця, під яким була виявлена ціль (рис. 3).

На завершення слід зауважити, що на обробку необхідно відбирати ті цілі, які здійснюють політ на висотах 8..12 км по трасі з якомога меншим параметром. Параметр має бути не більше ніж половина радіусу мертвої воронки на висоті польоту цілі

$$
p \leq 0,5 \frac{h_{u}}{\operatorname{tg}\left(\varepsilon_{\max }\right)},
$$

де $h_{u}$ - висота польоту цілі;

$$
\varepsilon_{\max } \text { - максимальний кут місця ДНА РЛС. }
$$


За виконання умови (9) ракурс цілі відносно РЛС в процесі їі польоту змінюється мало, а отже і відбивні властивості цілі залишаються незмінними.

\section{Висновки}

1. Проведення випробувань РЛС з використанням традиційних обльотів вимагає залучення значних коштів та матеріальних засобів і $\epsilon$ неприйнятним за умов обмеженого фінансування Збройних Сил України.

Крім того, за умов відсутності належної полігонної бази України такі випробування можуть бути проведені лише частково.

2. Багаторазові спроби суто теоретичних розрахунків зон виявлення повітряних об'єктів оглядовими РЛС довели їх практичну непридатність через неможливість врахування великої кількості випадко- вих чинників, які так чи інакше впливають на результати розрахунків.

3. Компромісним варіантом є застосування експериментально-розрахункових методів, які поєднують обмежений обсяг експериментальних даних 3 аналітичними розрахунками зон виявлення ПО.

4. В сучасних та перспективних РЛС, які мають розвинену систему документування, контроль необхідних параметрів зони виявлення цілей може бути здійснений без проведення обльотів спеціальними літальними апаратами через побіжне використання польотів рейсових ПО.

5. Визначення верхньої межі зони виявлення цілей може бути здійснене через використання практично отриманого запису рівня відбитого від цілі ехо-сигналу в процесі іiі супроводження для перерахунку кожної точки траси супроводження в точку верхньої крайки зони виявлення.

\section{Список літератури}

1. Перспективні шляхи розвитку лабораторно-випробувальної бази Збройних Сил України / І.М. Лаппо, Ю.М. Добришкін, О.В. Червотока, М.О. Геращенко // Збірник наукових праць Державного науково-дослідного інституту випробувань і сертифікації озброєння та військової техніки. - 2020. - № 3. - С. 67-76.

2. Камалтинов А.А. Аналіз існуючої експериментально-випробувальної бази України з випробувань наземних радіолокаційних засобів / Г.Г. Камалтинов, А.А. Курило // Збірник тез доповідей IX наукової конференції Харківського університету Повітряних Сил. - Харків, 14-15 квітня 2013 р. - С. 149.

3. Патент RU2400766C2 Российская Федерация. Способ испытания радиолокационной станции / Гурьев В.П., Лужных С.Н.; заявитель и патентообладатель Открытое акционерное общество "Научно-исследовательский институт измерительных приборов” (ОАО “НИИИП”).- № 2008146573/09; заявл. 25.11.2008; опубл. 27.09.2010, Бюл. № 27.

4. Аппаратно-программный комплекс для испытаний загоризонтных радиолокационных станций с использованием метода автоматического пассивного обзора воздушного пространства / С.А. Сорокин, С.С. Свердлов, Ю.С. Кучеров, В.А. Собчук // Вопросы радиоэлектроники. - 2018. - № 5. - С. 17-23. https://doi.org/10.21778/2218-5453-2018-5-17-23.

5. Савицкий Е.В. Модуль имитации целевой и помеховой обстановки для испытаний радиолокационных станций $/$ Е.В. Савицкий // Сборник материалов 54-й научной конференции аспирантов, магистрантов и студентов "Радиотехника и электроника". - Минск, 23-27 апреля 2018 г. - С. 103.

6. Імітатор повітряно-завадової обстановки з використанням системи “Віраж-РД” для оглядових аналогових радіолокаційних станцій / О.А. Малишев, М.Р. Арасланов, С.В. Бєлай, В.В. Сидоров, І.С. Бабенко, А.О. Астахов // Наука і техніка Повітряних Сил Збройних Сил України. - 2020. - № 4(41). - С. 112-124. https://doi.org/10.30748/nitps.2020.41.14.

7. Анализ опыта построения имитационных комплексов / А.А. Грызо, Д.А. Гриб, С.П. Лещенко // Системи обробки інформації. - 2006. - № 5(54). - С. 17-24.

8. Требования к удалению имитаторов активных помех при полигонных испытаниях РЛС / В.Ф. Зюкин, Д.Ю. Свистунов, А.В. Белавин // Системи обробки інформації. - 2013. - № 1(108). - С. 56-60.

9. Експериментально-розрахунковий метод оцінки параметрів зон виявлення первинних та вторинних РЛС / О.В. Бєлавін, Г.Г. Камалтинов, О.С. Маляренко // Наука і техніка Повітряних Сил Збройних Сил України. - 2012. № 3(9). - С. 69-73.

10. Климченко В.Й. Аналіз можливостей використання радіовипромінювання Сонця для зняття діаграм направленості антен сучасних РЛС розвідки повітряних цілей / В.Й. Климченко, Г.Г. Камалтинов, О.В. Бєлавін // Системи озброєння і військова техніка. - 2012. - № 3(31). - С. 63-68.

11. Doc. 8071 Manual on Testing of Radio Navigation Aids. Volume III Testing of Surveillance Radar Systems [Electronic resource]. - Montreal: ICAO, 1998. - Available at: https://www.worldcat.org/title/manual-on-testing-of-radio-navigation-aidsvoliii-testing-of-surveillance-radar-systems/oclc/841795216.

12. Barton D.K. Radar Sistem Analysis and Modeling / D.K. Barton. - Boston-London: Artech House, 2005. - 547 p.

13. Skolnik M.I. Radar Handbook / M.I. Skolnik. - New York: The McGraw-Hill Companies, 2008. - 1352 p. 
Відомості про авторів:

Климченко Василь Йонович

кандидат технічних наук доцент

провідний науковий співробітник

Харківського національного університету

Повітряних Сил ім. І. Кожедуба,

Харків, Україна

https://orcid.org/0000-0003-3999-8130

Маляренко Олександр Сергійович

кандидат технічних наук старший науковий співробітник провідний науковий співробітник

Харківського національного університету

Повітряних Сил ім. І. Кожедуба,

Харків, Україна

https://orcid.org/0000-0003-3268-3803

Бєлавін Олексій Вікторович

кандидат технічних наук

начальник відділу Командування Повітряних Сил

Збройних Сил України,

Вінниця, Україна

https://orcid.org/0000-0003-4217-2786

Рожков Микола Іванович

кандидат технічних наук доцент

старший науковий співробітник

Харківського національного університету

Повітряних Сил ім. І. Кожедуба,

Харків, Україна

https://orcid.org/0000-0002-8356-8659

\section{Information about the authors:}

Vasyl Klymchenko

Candidate of Technical Sciences

Associate Professor Lead Research

of Ivan Kozhedub Kharkiv

National Air Force University,

Kharkiv, Ukraine

https://orcid.org/0000-0003-3999-8130

\section{Oleksandr Maliarenko}

Candidate of Technical Sciences Senior Research

Lead Research

of Ivan Kozhedub Kharkiv National

Air Force University,

Kharkiv, Ukraine

https://orcid.org/0000-0003-3268-3803

\section{Oleksii Bielavin}

Candidate of Technical Sciences

Chief of Department of Air Force Command

of Armed Forces of Ukraine,

Vinnytsia, Ukraine

https://orcid.org/0000-0003-4217-2786

Mikola Rozhkov

Candidate of Technical Science Associate Professor

Senior Research Associate

of Ivan Kozhedub Kharkiv

National Air Force University,

Kharkiv, Ukraine

https://orcid.org/0000-0002-8356-8659

\title{
ОПРЕДЕЛЕНИЕ ВЕРХНЕЙ ГРАНИЦЫ ЗОНЫ ОБНАРУЖЕНИЯ ЦЕЛЕЙ ОБЗОРНЫМИ РЛС ЭКСПЕРИМЕНТАЛЬНО-АНАЛИТИЧЕСКИМ СПОСОБОМ
}

В.И. Климченко, А.С. Маляренко, А.В. Белавин, Н.И. Рожков

Рассматривается вариант сочетания аналитических расчетных методов определения зон обнаружения воздушных объектов (BO) с ограниченным объемом экспериментальных проверок, которые осуществляются путем облета специильными летательными аппаратами или же путем попутного использования полетов рейсовых ВО. Благодаря такому сочетанию, верхняя граница зоны может быть рассчитана по экспериментальным данным, полученным путем облета на одной заданной высоте специально выделенным самолетом, или же по данным сопровождения рейсовых самолетов, высота полета которых заблаговременно известна. Определение верхней границы зоны обнаружения ВО осуществляется путем анализа амплитуды принятых эхо-сигналов в процессе сопровождения специальных летательных аппаратов или рейсовых самолетов.

Ключевые слова: обзорные радиолокачионные станции, зона обнаружения воздушных объектов, облет, испытание.

\section{EXPERIMENTAL AND ANALYTICAL METHOD FOR DETERMINING THE UPPER LIMIT OF THE DETECTION AREA OF AIR OBJECTS BY RADARS IN THE PROCESS OF TESTING}

\author{
V. Klimchenko, O. Maliarenko O. Belavin, M. Rozhkov
}

Radar tests using traditional flight tests requires the attraction of significant funds and material resources and is problematic in the context of limited funding for the Armed Forces of Ukraine. In addition, due to the lack of a proper testing ground in Ukraine, such tests can only be partially carried out. There are also physical limitations in determining the shape and size of the surveillance radars air objects detection zone. The most difficult thing is to determine the configuration of its upper boundary due to the impossibility of flying at heights of several tens of kilometers. The well-known analytical methods for calculating the surveillance radars air objects detection zones determine to a greater extent only the potential capabilities of the radar and do not find their own application in practice due to the impossibility of taking into account a large number of random factors that somehow affect the results of calculations. A more acceptable option is a combination of analytical computational methods for determining the air objects detection zones with a limited amount of experimental tests, which are carried out by special aircraft flight tests or by passing flights of scheduled aircrafts. Thanks to this combination, the upper boundary of the zone can be calculated from experimental data obtained by flying a specially designated aircraft at one given altitude, or from scheduled aircraft tracking data, the flight altitude of which is known in advance. This requires the accumulation of data on the amplitude of the received echo signals during the tracking of special aircraft or scheduled aircraft. In modern and advanced radars, which have a developed documentation system, the accumulation of such data can be carried out for a long time, significantly exceeding the time spent by targets in the radar detection zone. Determination of the upper limit of the target detection zone is carried out by analyzing the amplitude of the received echo signals during the tracking of special aircraft or scheduled aircraft.

Keywords: surveillance radars, air objects detection zone, radar fight test, testing. 